\title{
Early versus Delayed Fortification of Human Milk in Preterm Infants: A Systematic Review
}

\author{
Wesam Alyahya $^{a}$ Judith Simpson ${ }^{\text {b, c }}$ Ada L. Garcia ${ }^{a}$ Helen Mactier ${ }^{d}$ \\ Christine A. Edwards ${ }^{a}$ \\ ${ }^{a}$ School of Medicine, Dentistry and Nursing, Human Nutrition, University of Glasgow, Glasgow, UK; ${ }^{b}$ Neonatal Unit, \\ Royal Hospital for Children, Glasgow, UK; ${ }^{\circ}$ NHS Greater Glasgow and Clyde Human Milk Bank, Queen Elizabeth \\ University Hospital, Glasgow, UK; ${ }^{d}$ Neonatal Unit, Princess Royal Maternity Hospital, Glasgow, UK
}

\section{Keywords}

Human milk fortifier · Human milk · Expressed breast milk ·

Premature infant · Preterm infant feeding

\begin{abstract}
Expressed breast milk (EBM) is commonly supplemented with commercially prepared human milk fortifier to meet the additional nutritional needs of preterm infants. The optimal milk intake at which to introduce fortification is unknown. The objective of this systematic review was to compare the effect of early fortification (EF) versus that of delayed introduction of human milk fortifier (DF) on short-term outcomes including growth, feeding intolerance, length of hospital stay, and maturity at discharge in very-low-birth-weight infants. The search was carried out until March 2019 using 5 electronic databases (PubMed, Ovid Medline, Web of Science, Ovid Embase, and the Cochrane Library). The search was supplemented with a search of the clinical trial registry and reference lists. Eligible studies involved randomized controlled trials that had been designed to compare EF against DF using multi-nutrient fortifier for infants of a birth weight of $<1,500 \mathrm{~g}$ who were fed exclusively or predominantly EBM. Four authors independently screened the stud-
\end{abstract}

ies for eligibility. A total of 1,972 articles were screened; 2 studies met the inclusion criteria and were included with a total number of participants of 171. The definition of EF and DF was not consistent between the 2 studies. There was no significant impact of EF versus DF on all outcomes. In conclusion, current data are limited and do not provide evidence on the optimal time to start fortification. The definition of EF and DF needs to be agreed upon and further larger randomized controlled trials are required.

(c) 2019 S. Karger AG, Basel

\section{Introduction}

The third trimester of pregnancy is a period of nutrient accretion and growth. Preterm infants have missed some or all of that period, and therefore their nutritional requirement is much higher than that of term infants. They accumulate significant nutrient deficiency in early postnatal life, which may result in growth restriction (weight below the 10th centile for postmenstrual age [PMA]). Poor growth is a very common problem in the preterm infant population, with poor postnatal growth found in $99 \%$ of extremely low-birth-weight infants [1], and can be

\section{KARGER}

(c) 2019 S. Karger AG, Basel 
associated with a higher risk for short-term morbidities [2-4]. Postnatal growth restriction has been associated with poorer neurodevelopmental outcomes and may continue to affect ex-preterm infants during later childhood and adulthood [5-7]. Expressed breast milk (EBM) confers numerous advantages for preterm infants, especially those born with a very low birth weight [8]. However, when fed as the only source of nutrition, EBM does not meet the preterm infant's increased nutritional requirements $[9,10]$. The protein requirement of growing preterm infants is between 3.5 and $4.5 \mathrm{~g} / \mathrm{kg} /$ day [11]. Feeding with $150 \mathrm{~mL} / \mathrm{kg} /$ day of unfortified EBM (often considered full enteral feeding) provides only about $1.8 \mathrm{~g} /$ $\mathrm{kg} /$ day of protein. Providing optimal early nutrition to preterm infants is challenging, but it can be facilitated by the use of multi-nutrient human milk fortifier (HMF). The addition of an HMF to EBM is recommended but there is no consensus on the timing at which HMF can safely be introduced and practice vary greatly. Fortification alters both the nutrient density and osmolality of EBM, which may affect intestinal peristalsis and feed tolerance, and increase the risk of necrotizing enterocolitis (NEC) [12]. Historically, this has been used as a justification for delaying the introduction of HMF. There is some evidence that these adverse outcomes may be more common with the use of bovine-based HMF, but the data are limited [13-15]. However, any risk needs to be balanced against the early introduction of HMF to avoid postnatal growth failure, which itself may have adverse neurodevelopmental consequences [16]. The aim of this systematic review was to compare in-hospital outcomes of early versus delayed introduction of multi-nutrient human milk fortifier. Outcomes of interest were short-term growth, feeding intolerance, length of hospital stay and PMA at discharge.

\section{Methods}

\section{Search}

Published literature was searched up to March 28, 2019 using five databases. The reference lists of the most relevant papers and reviews were searched manually. The clinical trial registration websites (clinicaltrial.gov) and Current Controlled Trials (isrctn. com) were searched for ongoing or completed trials. Abstracts were considered for inclusion only if they contained the necessary information. The search strategy was based on MeSH terms/subject headings and separate keywords. The MeSH terms were the following: fortified food, human milk, premature infant, growth and development, mortality, low birth weight, breast milk, and diet supplementation. The keywords were human milk, breast milk, and fortification. Boolean terms (AND, OR) were used to connect the search words. The study designs included were randomized or quasi-randomized controlled trials in the English language and there was no date restriction. Details of the systematic review protocol and search strategy are available in online supplementary material (Tables a and b; for all online suppl. material, see www. karger.com/doi/10.1159/000501279).

\section{Inclusion Criteria}

A study was eligible if it was a randomized or quasi-randomized controlled trial and the participants were both of very low birth weight $(<1,500 \mathrm{~g})$ and fed exclusively or predominantly with EBM (either mother's own milk [MOM] or pasteurized donor human milk). We only included studies designed to evaluate early fortification (i.e., added at small enteral volume) versus delayed fortification (i.e., added at larger enteral volume). At least one of our primary outcomes had to be measured. A study was excluded if it did not meet these criteria or included babies with congenital anomalies.

\section{Outcomes}

The primary outcomes of this systematic review were shortterm growth parameters (length, head growth, and weight gain), feeding intolerance (defined as clinical signs only and/or cessation of feeding), length of hospital stay (number of days that the baby remained in the neonatal unit), and PMA (i.e., gestational age plus chronological age) at discharge. Secondary outcomes were NEC and sepsis.

\section{Study Selection and Data Extraction}

To avoid bias in the study selection, the first reviewer (W.A.) screened all titles. Three other reviewers (C.E., A.L.G., and J.S.) screened all the titles again independently to make the final decision and ensure no study was missed. After that, W.A. reviewed the abstracts of all potentially relevant studies and obtained their full text. W.A. assessed full texts against the predetermined inclusion and exclusion criteria with the help of an inclusion checklist form (Appendix, form 1). Excluded studies were double-checked by two reviewers, C.E. and A.L.G. W.A. extracted the data from the studies meeting the inclusion criteria using data extraction sheet (Appendix, form 2). The following data items were extracted: publication year, authors, study settings, country where the study was carried out, design, participants, nutrition intervention, and outcomes of interest. Data were entered into Microsoft Excel.

\section{Individual Study Risk of Bias and Quality Assessment}

Three reviewers (W.A., C.E., and A.G.) independently assessed the risk of bias and the overall quality of each study. Criteria suggested by the Cochrane Collaboration tool were applied. Judgment for potential bias in each study methodology was classified as being of low, high or unclear risk according to the following domains: random sequence generation, allocation concealment, blinding of participants and personnel, blinding of outcome assessment, incomplete outcome data, and selective reporting [17]. The quality of each individual study was assessed using a scoring tool that we developed. The criteria for quality assessment considered the following aspects: the number of centres involved in the study, sample size, description of the intervention, reporting outcomes definition and method of measurement, study groups' homogeneity, and consideration of confounding factors. Details of our systematic review protocol are available in the supplementary material. 
Fig. 1. PRISMA flowchart.

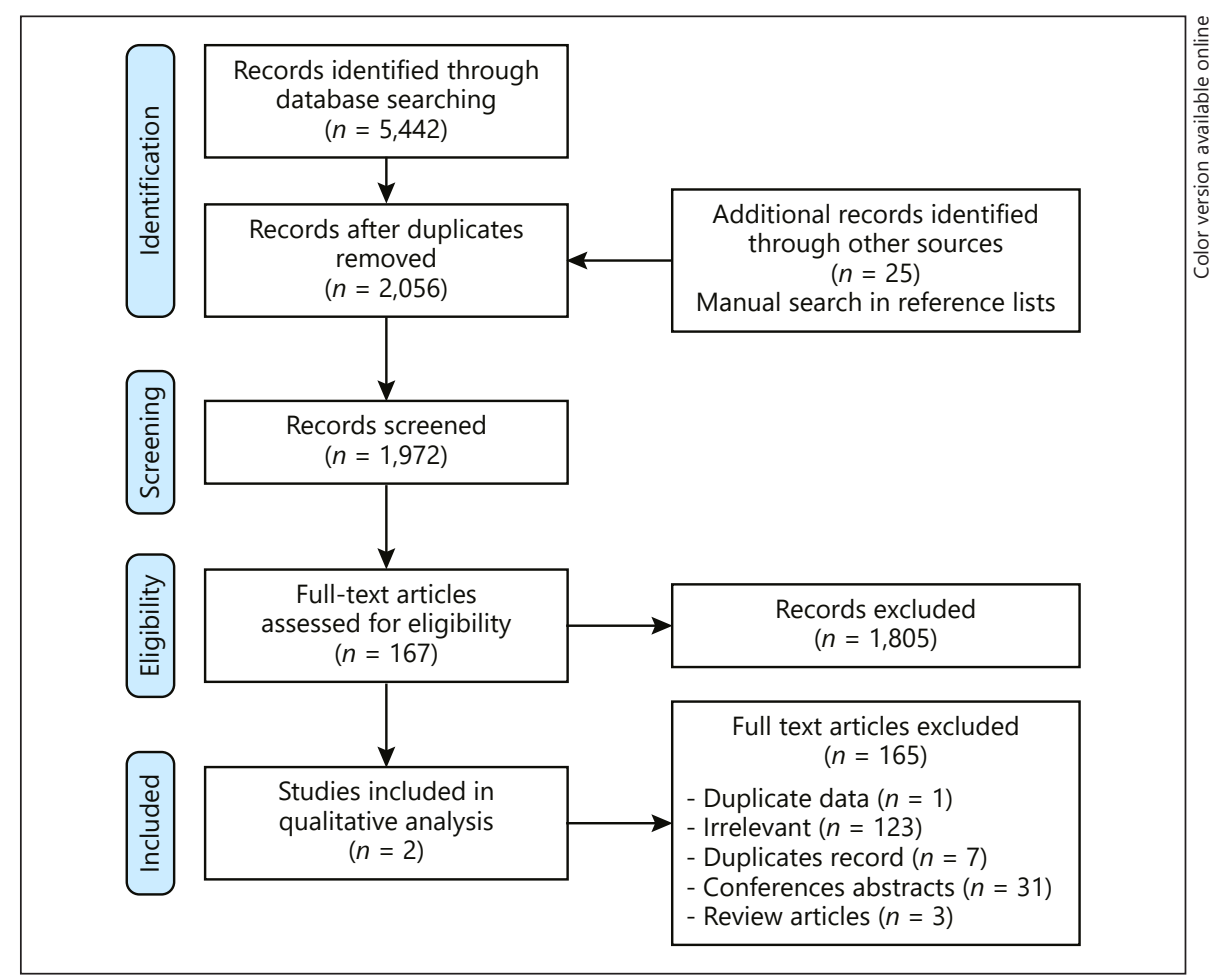

\section{Results}

\section{Searches}

Database searches returned 5,442 articles, and an additional 25 articles were found through a manual search. After duplicates were removed, the titles of 1,972 articles were screened for relevance, resulting in the exclusion of 1,805 articles. The remaining 167 articles were then assessed by reference to their full texts. After applying our eligibility criteria, 165 records were excluded, and 2 studies $[18,19]$ were included in this review (Fig. 1).

\section{Description of the Included Studies}

The studies' characteristics are summarized in Table 1. The initial sample size was 100 in the trial by Shah et al. [18] and 80 in the trial by Alizadeh et al. [19]. The studies occurred in two distinct geographical regions. One study was carried out in the USA between 2013 and 2015 [18], while the other was done in Iran between 2012 and 2013 [19]. Both studies were published in 2016. One study was conducted in two NICUs [18] and the other in one NICU [19]. Both studies included only preterm infants. In one study, the eligibility criteria included infants below $1,500 \mathrm{~g}$ at birth [18], while the other study allowed low birth weights $(<2,000 \mathrm{~g})$ to be included; this study was included in the review because the average birth weight of the participants was $1,295 \mathrm{~g}$. Both studies excluded infants with congenital anomalies. Infants in the study by Alizadeh et al. who had to be fed formula because of insufficient MOM supply were excluded. The average gestational age in the two studies was 29.1 weeks.

There was inconsistency in the definitions of early fortification (EF) and later or delayed fortification (DF) between the two studies. In the study by Shah et al., EF started at $20 \mathrm{~mL} / \mathrm{kg} /$ day and DF started at $100 \mathrm{~mL} / \mathrm{kg} /$ day. This study did not report the postnatal age at which fortification was initiated. In the study by Alizadeh et al., EF was reported as "first feeding" and DF was commenced at $75 \mathrm{~mL} / \mathrm{kg} /$ day. First feeding was described as starting on the "first day," as trophic feeding at a rate specific to birth weight and maturity level. They reported that the mean postnatal age at introduction of fortification in the EF group was 3.7 days.

Infants were fed exclusively with human milk in both studies. In the study by Shah et al., infants were fed both MOM and donated human milk. Infants in the DF group received a higher proportion of donated human milk than those in the EF group (67 vs. 54\%) but it was not reported if this was statistically significant. In the study by Alizadeh et al., infants were only fed MOM. In both studies, the fortifier used was of bovine origin and the method used for fortification was the addition of a standard amount for all babies rather than an individualized approach. Both trials 
Table 1. Characteristics of the included studies

Shah et al. [17]

Methods

Settings/study period

Objective
Two NICUs in USA/2013-2015

To compare human milk fortification at two different feeding volumes on time to reach full feeding and feeding intolerance

Participants

Inclusion criteria

Exclusion criteria

Randomized/analyzed, $n$

Gestational age

Birth weight

Nutrition management

Day EN started

EN advancement rate

Milk of feeding

Intervention description

Definition of EF

Definition of DF

Age at fortification

Fortifier name

Fortifier type

Fortifier dose

Duration of fortification

Fortified EBM energy density

Fortification method
Preterm, birth weight $<1,500 \mathrm{~g}$

Died or expected to die before $72 \mathrm{~h}$ of life,

major congenital or chromosomal

$100 / 99$

Median $(25$ th, 75th centile $)=27.8(26,30)^{1}$

Median $(25$ th, 75 th centile $)=990(810,1,225)^{1}$ abnormality, no MOM or refused DHM
Alizadeh et al. [18]

One NICU in Iran/2012-2013

Compare early versus delayed fortification on growth, feeding intolerance, sepsis, and NEC

$\begin{array}{ll}3(2.5,4) & \\ 10-20 \mathrm{~mL} / \mathrm{kg} / \text { day } & \text { One } \\ \text { MOM or DHM } & 10-20 \mathrm{~mL} / \mathrm{kg} / \text { day } \\ & \text { MOM }\end{array}$

Preterm, birth weight $<2,000 \mathrm{~g}$

Major congenital anomalies, transferred to another hospital, did not attend the neonatal clinic follow-up, had to be fed with formula due to insufficient MOM

$80 / 72$

Mean \pm standard deviation $=30.4 \pm 1.9^{1}$

Mean \pm standard deviation $=1,295 \pm 379^{1}$

NICU, neonatal intensive care unit; MOM, mother's own milk; DHM, donated human milk; HMF, human milk fortifier; EBM, expressed breast milk; NEC, necrotizing enterocolitis. ${ }^{1}$ Average value is calculated for the two study groups.

aimed to increase EBM caloric density to $24 \mathrm{kcal} / \mathrm{oz}$. Fortification was continued until the weight reached $3,000 \mathrm{~g}$ in the study by Alizadeh et al., but the study by Shah et al. did not report a criterion for discontinuing fortification.

The definition of NEC, feeding intolerance, and sepsis outcomes varied between the two studies. In the study by Shah et al., feeding intolerance was defined as symptoms or signs leading to feeding cessation, whereas in the study by Alizadeh et al., it was defined as signs of feeding intolerance only. NEC was defined in the study by Shah et al. using Bell's criteria (stage II or more), but the other study used a list of clinical, laboratory and radiological diagnostic criteria. In the study by Shah et al., sepsis was defined by clinical signs of sepsis proven by blood culture, where- as the other study defined it by clinical signs only. Definitions for all reported outcomes are listed in the online supplementary file (Table e).

\section{Individual Studies' Risks of Bias and Quality}

Assessments

There was a low risk of selection bias in the study by Shah et al. In the study by Alizadeh et al., the risk of selection bias was unclear, as no details were provided on the tool used to perform block randomization, and the allocation was concealed. There was a high risk of performance bias in the trial by Shah et al., as the blinding of infants' caregivers and the research investigator was not possible due to the fortification of EBM occurring at the bedside. In the trial by Aliza- 
Table 2. Risk of bias assessment

\begin{tabular}{|c|c|c|c|c|}
\hline \multirow[t]{2}{*}{ Domain } & \multicolumn{2}{|l|}{ Shah et al. [17] } & \multicolumn{2}{|c|}{ Alizadeh et al. [18] } \\
\hline & $\begin{array}{l}\text { review authors' } \\
\text { judgement }\end{array}$ & support for judgement & $\begin{array}{l}\text { review authors' } \\
\text { judgement }\end{array}$ & support for judgement \\
\hline \multicolumn{5}{|l|}{ Selection bias } \\
\hline $\begin{array}{l}\text { Random sequence } \\
\text { generation }\end{array}$ & Low risk & $\begin{array}{l}\text { Use of blocked stratified randomization } \\
\text { approach by computerized software }\end{array}$ & Unclear risk & $\begin{array}{l}\text { Block randomization method, } \\
\text { no details how }\end{array}$ \\
\hline Allocation concealment & Low risk & $\begin{array}{l}\text { The research coordinator and principal } \\
\text { investigator performed the enrolment and } \\
\text { assignment of infants after randomization }\end{array}$ & Unclear risk & Double blinded, no details how \\
\hline \multicolumn{5}{|l|}{ Performance bias } \\
\hline $\begin{array}{l}\text { Blinding of participants and } \\
\text { personnel (all outcomes) }\end{array}$ & High risk & $\begin{array}{l}\text { Infants' caregiver and research } \\
\text { investigators were not blinded; } \\
\text { Fortification (intervention) occurred at } \\
\text { bedside, blinding was not possible }\end{array}$ & Unclear risk & $\begin{array}{l}\text { It was not reported if the } \\
\text { caregiver and researcher were } \\
\text { blinded }\end{array}$ \\
\hline \multicolumn{5}{|l|}{ Detection bias } \\
\hline $\begin{array}{l}\text { Blinding of outcome } \\
\text { assessment }\end{array}$ & Unclear risk & $\begin{array}{l}\text { Was not clearly reported if the outcomes } \\
\text { measurers were blinded }\end{array}$ & Unclear risk & $\begin{array}{l}\text { It is unclear if the outcome } \\
\text { measurer was blinded at the } \\
\text { time of outcome measurement }\end{array}$ \\
\hline \multicolumn{5}{|l|}{ Attrition bias } \\
\hline Incomplete outcome data & Low risk & $99 \%$ of the participant were analysed & Low risk & $\begin{array}{l}90 \% \text { of the participant were } \\
\text { analysed }\end{array}$ \\
\hline \multicolumn{5}{|l|}{ Reporting bias } \\
\hline Selective reporting & Low risk & Outcomes were reported & Low risk & Outcomes were reported \\
\hline
\end{tabular}

deh et al., the risk of performance bias was unclear, as no details were provided. The risk of detection bias was unclear in both studies. There was a low risk of attrition bias in both studies, as most of the participants remained in the study until the intervention ended ( $90 \%$ in the study by Alizadeh et al. and $99 \%$ in the study by Shah et al.). No selective reporting was observed in either trial (Table 2). Shah's study was evaluated to be of high quality, while the other study was evaluated to be of moderate quality (Table 3 ).

\section{Effect of EF versus DF on Outcomes}

Most of the primary and secondary outcomes were measured in both studies with the exception of length of hospital stay, which was reported by only one study (Shah's study). Neither study reported PMA at discharge. The primary outcome in the study by Shah et al. was days to reach full feeding, while in-hospital growth was the primary outcome in Alizadeh's study. Due to the small number of included studies, meta-analysis was not performed. Data on all primary outcomes except length of stay were available for 171 infants in the two trials. Length-of-stay data were available for 99 infants in the trial by Shah et al. Neither study reported differences between groups including NEC or sepsis (Table 4).

\section{Discussion and Conclusion}

The main finding of this systematic review is that there is insufficient evidence to evaluate the effects of EF against DF of human milk in very-low-birth-weight infants. Despite screening a large number of international studies using a robust search strategy, we found little evidence on the benefits of EF versus DF. The number of studies was small, and the definitions of EF and DF varied. In one of the included trails, by Shah et al., the primary outcome was days to achieve full feeding volume. They showed that the median days to achieve full feeding and the number of events of feeding intolerance were similar in the EF and DF groups. Some published studies that did not meet our inclusion criteria showed some benefits of EF. One observational study compared EF ( $80 \mathrm{~mL} / \mathrm{kg} /$ day $)$ with DF $(160 \mathrm{~mL} / \mathrm{kg} /$ day $)$ in late preterm infants and found that infants in the EF group regained their birth weight faster and had fewer events of feeding intolerance [19]. A clinical trial by Sullivan et al. [20] (which was not designed to compare EF with DF) showed that fortification with human-milk-based fortifier was tolerated at $40 \mathrm{~mL} / \mathrm{kg} /$ day. An observational study by Tillman et al. [21] showed that EF (from the first feeding) improved bone mineralization (lower alkaline phosphate) 
Table 3. Quality assessment of the included studies

\begin{tabular}{|c|c|c|c|c|}
\hline & \multicolumn{2}{|c|}{ Shah et al. [17] } & \multicolumn{2}{|c|}{ Alizadeh et al. [18] } \\
\hline & score & rationale & score & rationale \\
\hline Multi-centre & 1 & Two centres & 0 & One centre \\
\hline Sample size & 1 & 99 infants included & 1 & 72 infants included \\
\hline $\begin{array}{l}\text { Description of } \\
\text { intervention }\end{array}$ & 2 & $\begin{array}{l}\text { EF and DF were clearly } \\
\text { defined as } \mathrm{mL} / \mathrm{kg} / \text { day }\end{array}$ & 1 & $\begin{array}{l}\text { EF was defined as "first } \\
\text { feeding," specific volume } \\
\text { was not reported }\end{array}$ \\
\hline $\begin{array}{l}\text { Baseline characteristics } \\
\text { comparable }\end{array}$ & 1 & $\begin{array}{l}\text { EF and DF groups had } \\
\text { similar demographic }\end{array}$ & 1 & $\begin{array}{l}\text { EF and DF groups had } \\
\text { similar demographic }\end{array}$ \\
\hline Outcomes defined & 1 & Yes & 1 & Yes \\
\hline $\begin{array}{l}\text { Outcomes measurement } \\
\text { described }\end{array}$ & 1 & Yes & 0 & Yes \\
\hline Confounding factors & 1 & $\begin{array}{l}\text { RCT but 13\% } \\
\text { difference in donated } \\
\text { human milk intake } \\
\text { between groups; not } \\
\text { reported if statistically } \\
\text { significant }\end{array}$ & 1 & RCT \\
\hline Score (quality level) & 8 (high) & & $5(\mathrm{mo}$ & \\
\hline
\end{tabular}

Table 4. Effect of EF versus DF on outcomes

\begin{tabular}{|c|c|c|c|c|}
\hline Outcome and study & Unit & Early fortification & Delayed fortification & $p$ value \\
\hline \multicolumn{5}{|l|}{ Weight gain, g/kg/day } \\
\hline Shah, 4 weeks of life & Median (IQR) & $8.7(6.4,12.2)$ & $7.7(5.1,10.6)$ & 0.08 \\
\hline Shah, 36 weeks PMA & Median (IQR) & $18.3(14.9,20.7)$ & $16.7(13.9,22)$ & 0.3 \\
\hline Alizadeh & z score & $-1.24(-3.74$ to 0.84$)$ & $-1.23(-3.92$ to 1.16$)$ & 0.864 \\
\hline \multicolumn{5}{|l|}{ Head growth } \\
\hline Shah, 4 weeks of life & Mean (SD) & $-0.97(0.91)$ & $-0.95(1.0)$ & 0.90 \\
\hline Shah, 36 weeks PMA & Mean (SD) & $-0.71(1.08)$ & $-0.65(1.07)$ & 0.80 \\
\hline Alizadeh & z score & $-5.15(-0.95$ to 1.66$)$ & $-0.43(-2.77$ to 1.10$)$ & 0.787 \\
\hline \multicolumn{5}{|l|}{ Length gain } \\
\hline Shah, 4 weeks of life & Mean (SD) & $-1.0(0.57)$ & $0.97(0.69)$ & 0.81 \\
\hline Shah, 36 weeks PMA & Mean (SD) & $-1.58(0.93)$ & $1.59(0.89)$ & 0.93 \\
\hline Alizadeh & $\mathrm{z}$ score & $-0.14(-3.74$ to 2.26$)$ & $-0.44(-4.11$ to 1.82$)$ & 0.348 \\
\hline \multicolumn{5}{|l|}{ Feeding intolerance } \\
\hline Shah & $n(\%)$ & $15(31)$ & $15(30)$ & 1 \\
\hline Alizadeh & $n(\%)$ & $5(14)$ & $3(9)$ & 0.771 \\
\hline \multicolumn{5}{|c|}{ Length of hospital stay, days } \\
\hline Shah & Median (IQR) & $68(41,101)$ & $63(50,83)$ & 0.49 \\
\hline \multicolumn{5}{|l|}{ Necrotizing enterocolitis } \\
\hline Shah & $n(\%)$ & $2(4)$ & $2(4)$ & 1 \\
\hline Alizadeh & $n(\%)$ & $2(6)$ & 0 & 0.223 \\
\hline \multicolumn{5}{|l|}{ Sepsis } \\
\hline Shah & $n(\%)$ & $3(6)$ & $6(12)$ & 0.49 \\
\hline Alizadeh & $n(\%)$ & $2(6)$ & $1(3)$ & 0.572 \\
\hline
\end{tabular}

IQR, interquartile range; SD, standard deviation. The number of participants analysed for all outcomes in the study by Shah et al. $(\mathrm{EF}=49, \mathrm{DF}=50)$ and in the study by Alizadeh et al. $(\mathrm{EF}=36, \mathrm{DF}=36)$. 
and did not have higher events of feeding intolerance. Nevertheless, proper randomized clinical trials designed to evaluate the effectiveness and safety of EF in high-risk infants are needed to inform feeding practice.

Although optimizing nutrition for preterm infants is advantageous in terms of improved short-term growth, there remains a lack of evidence on the longer-term benefits of fortification of EBM. A recently published Cochrane meta-analysis comparing the growth and developmental outcomes of using fortified EBM against unfortified EBM found insufficient data from which to draw any meaningful conclusions [22]. Despite a rigorous search methodology, the authors concluded that there is limited evidence for evaluating the benefits of multi-nutrient fortification of EBM against unfortified EBM.

In summary, current evidence does not provide guidance on the optimal time to start fortification. Further and larger randomized clinical trials comparing the effect of EF versus DF are needed. Future studies should measure core outcomes that are important for both parents and health professionals to allow results to be compared and combined [23].

\section{Acknowledgement}

This work was supported by the Faculty of Applied Medical Sciences, the Clinical Nutrition Department at Imam Abdurrahman Bin Faisal University, Dammam, the Kingdom of Saudi Arabia.

\section{Statement of Ethics}

The authors have no ethical conflicts to disclose.

\section{Disclosure Statement}

C.A.E. has been involved in workshops for ILSI Europe. The other authors have indicated they have no potential conflicts of interest to disclose.

\section{Funding Sources}

This work is part of a PhD study and funded by the Royal Embassy of Saudi Arabia Cultural Bureau.

\section{Author Contributions}

Mrs. Alyahya conceptualized and designed the systematic review, carried out the searches, screened the studies, assessed the full text, extracted the data, carried out the analysis, and drafted and revised the manuscript.

Prof. Edwards and Dr. Garcia conceptualized and designed the systematic review, screened the studies, supervised the data extraction and analysis and critically reviewed the manuscript.

Dr. Simpson screened the studies and reviewed the analysis and critically reviewed the manuscript.

Dr. Mactier conceptualized and designed the systematic review and critically reviewed the manuscript.

All the authors approved the final manuscript as submitted and agree to be accountable for all aspects of the work.

\section{Appendix}

\begin{tabular}{|c|c|c|c|}
\hline \multicolumn{4}{|l|}{ Form 1: Eligibility checklist } \\
\hline Criteria & & Yes & No \\
\hline \multirow[t]{3}{*}{ Participants } & Were study participants VLBW preterm infants? & & \\
\hline & Did participants have any congenital problems? & & \\
\hline & $\begin{array}{l}\text { Were infants fed exclusively or predominantly ( }>50 \% \text { of enteral feeding) with EBM (mothers' own } \\
\text { milk or donated human milk) during the study period? }\end{array}$ & & \\
\hline Settings & Did the study take place in neonatal intensive care units or a special care baby unit? & & \\
\hline Study design & Was the study designed to be randomized controlled trials or quasi-randomized controlled trials? & & \\
\hline Interventions or exposures & Was the aim of the study to test early versus delayed fortification of EBM? & & \\
\hline \multirow[t]{9}{*}{ Outcomes measurement } & Was any of the following outcomes measured? & & \\
\hline & Primary: & & \\
\hline & Short-term growth parameters [length, head growth, and weight gain] & & \\
\hline & Feeding intolerance & & \\
\hline & Length of hospital stay & & \\
\hline & Post-menstrual age (PMA) at discharge (i.e. gestational age plus chronological age) & & \\
\hline & Secondary: & & \\
\hline & Necrotizing enterocolitis & & \\
\hline & Sepsis & & \\
\hline \multicolumn{4}{|l|}{ Decision to include study } \\
\hline Reason for exclusion & & & \\
\hline
\end{tabular}




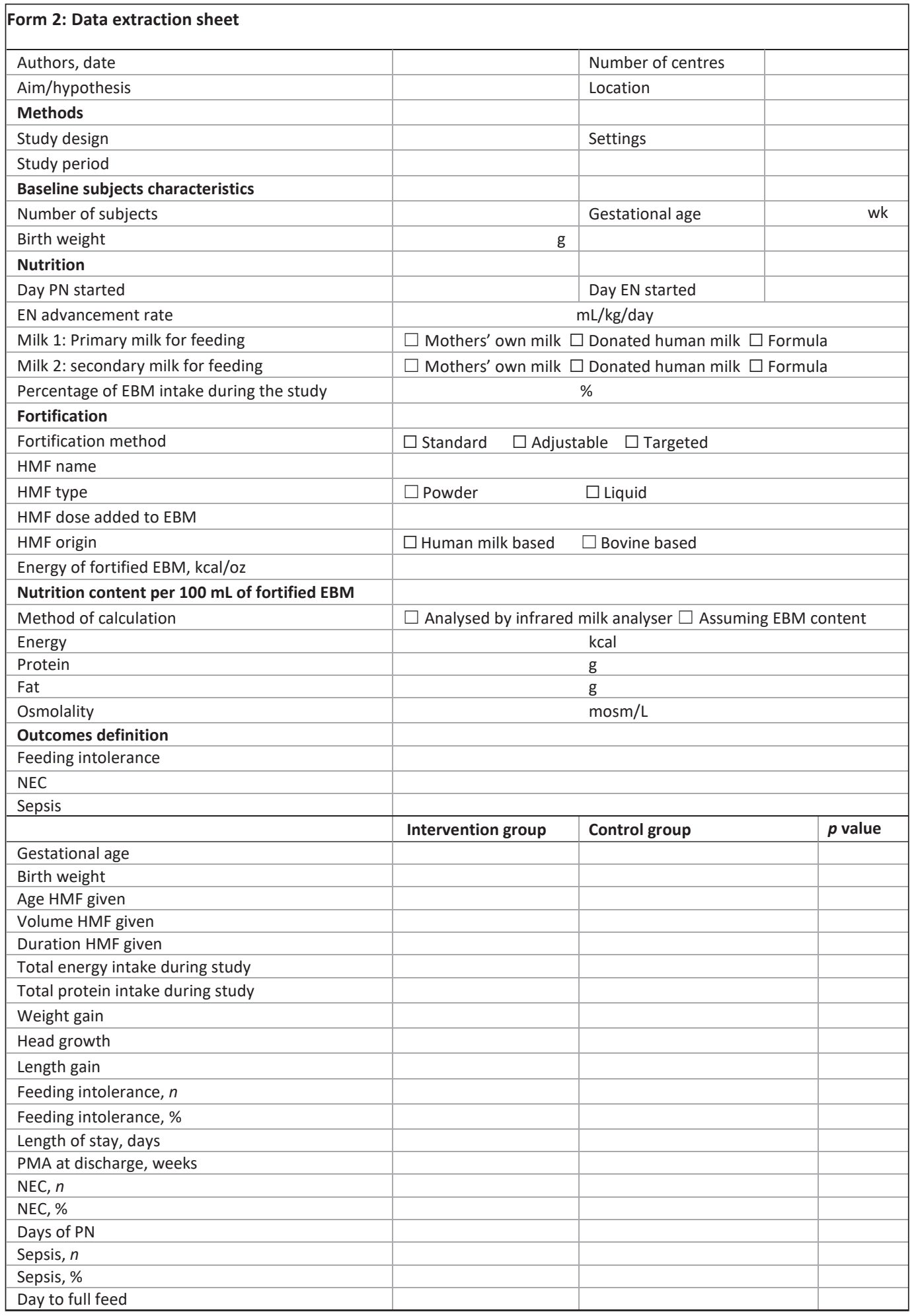




\section{References}

1 Lemons JA, Bauer CR, Oh W, Korones SB, Papile LA, Stoll BJ, et al.; NICHD Neonatal Research Network. Very low birth weight outcomes of the National Institute of Child health and human development neonatal research network, January 1995 through December 1996. Pediatrics. 2001 Jan;107(1):E1.

2 Sices L, Wilson-Costello D, Minich N, Friedman H, Hack M. Postdischarge growth failure among extremely low birth weight infants: correlates and consequences. Paediatr Child Health. 2007 Jan;12(1):22-8.

3 Embleton NE, Pang N, Cooke RJ. Postnatal malnutrition and growth retardation: an inevitable consequence of current recommendations in preterm infants? Pediatrics. 2001 Feb;107(2):270-3.

4 Costeloe KL, Hennessy EM, Haider S, Stacey F, Marlow N, Draper ES. Short term outcomes after extreme preterm birth in England: comparison of two birth cohorts in 1995 and 2006 (the EPICure studies). BMJ. 2012 Dec 4;345:e7976.

5 Euser AM, Finken MJ, Keijzer-Veen MG, Hille ET, Wit JM, Dekker FW; Dutch POPS19 Collaborative Study Group. Associations between prenatal and infancy weight gain and BMI, fat mass, and fat distribution in young adulthood: a prospective cohort study in males and females born very preterm. Am J Clin Nutr. 2005 Feb;81(2):480-7.

6 Saigal S, Doyle LW. An overview of mortality and sequelae of preterm birth from infancy to adulthood. Lancet. 2008 Jan;371(9608):261-9.

7 Ehrenkranz RA, Dusick AM, Vohr BR, Wright LL, Wrage LA, Poole WK. Growth in the neonatal intensive care unit influences neurodevelopmental and growth outcomes of extremely low birth weight infants. Pediatrics. 2006 Apr;117(4):1253-61.
8 Tudehope DI. Human milk and the nutritional needs of preterm infants. J Pediatr. 2013 Mar;162(3 Suppl):S17-25.

9 Simpson JH, McKerracher L, Cooper A, Barnett D, Gentles E, Cairns L, et al. Optimal Distribution and Utilization of Donated Human Breast Milk: A Novel Approach. J Hum Lact. 2016;32(4).DOI: 10.1177/0890334416653738.

10 Ballard O, Morrow AL. Human milk composition: nutrients and bioactive factors. Pediatr Clin North Am. 2013 Feb;60(1):49-74.

11 Agostoni C, Buonocore G, Carnielli VP, De Curtis M, Darmaun D, Decsi T, et al.; ESPGHAN Committee on Nutrition. Enteral nutrient supply for preterm infants: commentary from the European Society of Paediatric Gastroenterology, Hepatology and Nutrition Committee on Nutrition. J Pediatr Gastroenterol Nutr. 2010 Jan;50(1):85-91.

12 Ewer AK, Yu VY. Gastric emptying in preterm infants: the effect of breast milk fortifier. Acta Paediatr. 1996 Sep;85(9):1112-5.

13 Sullivan S, Schanler RJ, Kim JH, Patel AL, Trawöger R, Kiechl-Kohlendorfer U, et al. An exclusively human milk-based diet is associated with a lower rate of necrotizing enterocolitis than a diet of human milk and bovine milk-based products. J Pediatr. 2010;156(4): 562-7.

14 Abrams SA, Schanler RJ, Lee ML, Rechtman DJ. Greater mortality and morbidity in extremely preterm infants fed a diet containing cow milk protein products. Breastfeed Med. 2014 Jul-Aug;9(6):281-5.

15 Ghandehari H, Lee ML, Rechtman DJ; H2MF Study Group. An exclusive human milkbased diet in extremely premature infants reduces the probability of remaining on total parenteral nutrition: a reanalysis of the data. BMC Res Notes. 2012 Apr;5(1):188.
16 Ong KK, Kennedy K, Castañeda-Gutiérrez E, Forsyth S, Godfrey KM, Koletzko B, et al. Postnatal growth in preterm infants and later health outcomes: a systematic review. Acta Paediatr. 2015 Oct; 104(10):974-86.

17 Higgins JP. Cochrane Handbook for Systematic Reviews of Interventions Version 5.1.0: The Cochrane Collaboration; 2011. Available from: http://handbook-5-1.cochrane.org/.

18 Shah SD, Dereddy N, Jones TL, Dhanireddy R, Talati AJ. Early versus Delayed Human Milk Fortification in Very Low Birth Weight Infants-A Randomized Controlled Trial. J Pediatr. 2016 Jul;174:126-131.e1.

19 Alizadeh Taheri P, Sajjadian N, Asgharyan Fargi M, Shariat $M$. Is early breast milk fortification more effective in preterm infants?: a clinical trial. J Perinat Med. 2017 Nov 27; 45(8):953-57.

20 Sullivan S, Schanler RJ, Kim JH, Patel AL, Trawöger R, Kiechl-Kohlendorfer U, et al. An exclusively human milk-based diet is associated with a lower rate of necrotizing enterocolitis than a diet of human milk and bovine milk-based products. J Pediatr. 2010 Apr; 156(4):562-7.e1.

21 Tillman S, Brandon DH, Silva SG. Evaluation of human milk fortification from the time of the first feeding: effects on infants of less than 31 weeks gestational age. J Perinatol. 2012 Jul; 32(7):525-31.

22 Brown JV, Embleton ND, Harding JE, McGuire W. Multi-nutrient fortification of human milk for preterm infants. Cochrane Database Syst Rev. 2016 May;(5):CD000343.

23 Webbe J, Brunton G, Ali S, Duffy JM, Modi N, Gale C. Developing, implementing and disseminating a core outcome set for neonatal medicine. BMJ Paediatr Open. 2017; 1(1):e000048-e. 